\title{
Kinetics of pyrophosphate-driven proton uptake by acidocalcisomes of Leptomonas wallacei ${ }^{\text {出 }}$
}

\author{
Bernardo Luiz Moraes Moreira ${ }^{a}$, Lia Carolina A. Soares Medeiros ${ }^{\text {a }}$, Kildare Miranda ${ }^{\text {b,c }}$, \\ Wanderley de Souza ${ }^{\mathrm{b}}$, Joachim Hentschel ${ }^{\mathrm{d}}$, Helmut Plattner ${ }^{\mathrm{d}}$, Hector Barrabin ${ }^{\mathrm{a}, *}$ \\ ${ }^{a}$ Instituto de Bioquímica Médica, Programa de Biologia Estrutural, Universidade Federal do Rio de Janeiro, Brazil \\ ${ }^{\mathrm{b}}$ Laboratório de Ultraestrutura Celular Hertha Meyer, Instituto de Biofísica Carlos Chagas Filho, Universidade Federal do Rio de Janeiro, Brazil \\ ${ }^{\mathrm{c}}$ Laboratório de Biologia Celular e Tecidual, Centro de Biociências e Biotecnologia, Universidade Estadual do Norte Fluminense Darcy Ribeiro, Brazil \\ ${ }^{\mathrm{d}}$ Lehrstuhl f. Zellbiologie und Ultrastrukturforschung, Fachbereich Biologie, Universität Konstanz, Konstanz, Germany
}

\begin{abstract}
In this work, we show the kinetics of pyrophosphate-driven $\mathrm{H}^{+}$uptake by acidocalcisomes in digitonin-permeabilized promastigotes of Leptomonas wallacei. The vacuolar proton pyrophosphatase activity was optimal in the $\mathrm{pH}$ range of 7.5-8.0, was inhibited by imidiodiphosphate, and was completely dependent on $\mathrm{K}^{+}$and $\mathrm{PPi} . \mathrm{H}^{+}$was released with the addition of $\mathrm{Ca}^{2+}$, suggesting the presence of a Ca ${ }^{2+} / \mathrm{H}^{+}$antiport. In addition, X-ray elemental mapping associated with energy-filtering transmission electron microscopy showed that most of the $\mathrm{Ca}, \mathrm{Na}, \mathrm{Mg}, \mathrm{P}, \mathrm{K}, \mathrm{Fe}$, and $\mathrm{Zn}$ were located in acidocalcisomes. L. wallacei immunolabeled with antibodies against Trypanosoma cruzi pyrophosphatase show intense fluorescence in cytoplasmatic organelles of size and distribution similar to the acidocalcisomes. Altogether, the results show that $L$. wallacei acidocalcisomes possess a $\mathrm{H}^{+}$-pyrophosphatase with characteristics of type I V-H $\mathrm{H}^{+}$-PPase. However, we did not find any evidence, either for the presence of $\mathrm{H}^{+}$-ATPases or for $\mathrm{Na}^{+} / \mathrm{H}^{+}$exchangers in these acidocalcisomes.
\end{abstract}

Keywords: Pyrophosphatase; Acidocalcisome; Tripanosomatid; Leptomonas; Proton transport; Iron; Zinc; Calcium; Vacuole; $\mathrm{H}^{+}$-PPase

The trypanosomatidae family comprises unicellular eukaryotes that are able to infect a broad range of organisms such as mammalians, fishes, plants, and insects causing a wide spectrum of diseases of social, economical, and medical importance. Leptomonas wallacei is a trypanosomatid parasite that was first isolated by Romeiro et al. [1] from the intestinal tract of the phytophagous hemipteran Oncopeltus fasciatus and since then has been used as a model for studies of the interaction between trypanosomatids and the midgut of the in-

\footnotetext{
is Abbreviations: $\mathrm{PPi}$, pyrophosphate; polyP, polyphosphates; $\mathrm{V}-\mathrm{H}^{+}$PPase, vacuolar-proton-pyrophosphatase; IDP, imidodiphosphate; PBS, phosphate-buffered saline; $\mathrm{AO}$, acridine orange; $\mathrm{NH}_{4} \mathrm{Cl}$, ammonium chloride; NEM, $N$-ethyl-maleimide; $\mathrm{NaF}$, sodium fluoride.

* Corresponding author. Fax: +55 2122708647.

E-mail address: barrabin@bioqmed.ufrj.br (H. Barrabin).
}

sect vector [2,3]. A remarkable characteristic of these parasites is their ability to form cysts. They occur mainly as promastigotes but can differentiate into cystic forms, which suggests that they represent latent forms of the parasite, protecting it from extreme environmental conditions [1], which include variations on the concentration of ionic species, osmotic pressure, and $\mathrm{pH}$, faced by the parasite in the different portions of the insect gut during the course of infection.

Control of intracellular $\mathrm{pH}$ in trypanosomatids occurs through the action of proton uptake/release mechanisms located either in the plasma membrane or in intracellular compartments. These include electrogenic proton pumps, proton/ion exchangers, and $\mathrm{HCO}_{3}{ }^{-}$ and chloride channels [4]. The electrogenic proton pumps comprise the P-type proton ATPase (P-ATPase) 
[5], the vacuolar proton ATPase (V-ATPase) [6,7], and the vacuolar proton pyrophosphatase (V-PPase) [8-10]. The first one has been shown to localize to the plasma membrane and to intracellular compartments of unknown nature $[5,11]$ and the other two to the plasma membrane and to the acidocalcisomes [6-10].

Acidocalcisomes are calcium-rich acidic organelles first described in Trypanosoma brucei [6] and Trypanosoma cruzi [12], and then in several other trypanosomatids such as Leishmania [10,13,14], Phytomonas [11,15], Herpetomonas [16], Crithidia, Blastocrithidia, and Leptomonas [17], in apicomplexan parasites such as Plasmodium [18,19] and Toxoplasma [20-22], in other unicellular organisms such as Chlamydomonas reinhardtii [23], Dictyostelium discoideum [24], and in the bacteria Agrobacterium tumefaciens [25] and Rhodospirillum rubrum [26]. Acidification of acidocalcisomes is promoted by a V-type proton ATPase (V-H ${ }^{+}$-ATPase) $[27,28]$ and a V-type pyrophosphatase (V-H ${ }^{+}$-PPase) $[8,10]$. They also possess a $\mathrm{Ca}^{2+}-\mathrm{H}^{+}$-translocating ATPase [29] for calcium uptake, a $\mathrm{Ca}^{2+} / \mathrm{H}^{+}$antiporter for calcium release [6], and a $\mathrm{Na}^{+} / \mathrm{H}^{+}$antiporter for $\mathrm{Na}^{+}$uptake [30]. From the structural point of view, acidocalcisomes are electron dense organelles that contain a large amount of sodium, magnesium, phosphorus, potassium, calcium, iron, and zinc [14,15,31-34]. Phosphorous compounds are present primarily as pyrophosphates and long and short chains of polyphosphates [23] and may participate as a cationbinding component $[33,35]$.

One of the functions attributed to the acidocalcisomes in heteroxenic parasites is a role in the adaptation of the parasites to different environmental challenges such as differences in extracellular $\mathrm{pH}$, ionic composition, and temperature, found in the different hosts in the course of infection. The mechanisms of $\mathrm{pH}$ control by acidocalcisomes are particularly important for L. wallacei because variations of extracellular $\mathrm{pH}$ may lead to differentiation from promastigotes into cystic forms. Therefore, a detailed characterization of the physiologic properties of the mechanisms of proton uptake by acidocalcisomes of $L$. wallacei might be important for the understanding of the mechanisms underlying the environmental adaptation by this parasite.

In a previous work, we reported the structural properties and the elemental composition of acidocalcisomes in L. wallacei [17]. In the present work, a pyrophosphate-driven proton uptake in acidocalcisomes of promastigote forms of $L$. wallacei was characterized. The distribution of acidocalcisomes was determined by $\mathrm{X}$-ray elemental mapping associated with energy filtering transmission electron microscopy and the distribution of the V-H $\mathrm{H}^{+}$-PPase was determined by immunofluorescence microscopy using antibodies raised against a peptide sequence of $T$. cruzi $\mathrm{H}^{+}$-PPase. Images showed a labeling pattern in intracellular vacuoles numerically consistent with the dense granules (acidocalcisomes) seen in whole cells imaged by transmission electron microscopy. Kinetics of $\mathrm{H}^{+}$uptake by the $\mathrm{V}-\mathrm{H}^{+}$-PPase showed that this activity is dependent on potassium ions, inhibited by IDP, insensitive to sodium and sucrose, and has maximal activity in the $\mathrm{pH}$ range 7.5-8.0, suggesting that this enzyme belongs to the type I V-H ${ }^{+}$-PPase. In addition, a $\mathrm{Ca}^{2+} / n \mathrm{H}^{+}$counter-transporting system that may participate in $\mathrm{Ca}^{2+}$ uptake by acidocalcisomes was detected. Neither $\mathrm{H}^{+}$-ATPase activity nor a $\mathrm{Na}^{+} / \mathrm{H}^{+}$exchanger could be detected in intracellular compartments in these cells. Altogether, the data presented here provide evidence that the mechanisms of $\mathrm{pH}$ stasis, ion storage, and homeostasis performed by the acidocalcisomes in L. wallacei are similar to those so far described for other trypanosomatids which are unable to differentiate into cystic forms.

\section{Materials and methods}

Culture method. Leptomonas wallacei promastigotes (CT-IOC 194; kindly provided by Dr. Alexandre Romeiro-Instituto de Biofísica Carlos Chagas Filho, UFRJ, RJ-Brazil) were grown at room temperature $\left(25-27^{\circ} \mathrm{C}\right)$ in a medium containing $37 \mathrm{~g} / \mathrm{L}$ of brain heart infusion (BHI), $1 \mathrm{mg} / \mathrm{L}$ folic acid, supplemented with $10 \mathrm{mg} / \mathrm{L}$ haemin and $10 \%(\mathrm{v} / \mathrm{v})$ fetal bovine serum. At 2-3 days after inoculation, cells were harvested by centrifugation, washed twice with $5 \mathrm{mM}$ phosphate buffer, $\mathrm{pH} 7.0$, containing $150 \mathrm{mM} \mathrm{KCl}$ (PBS), and resuspended in the same solution.

Electron probe $X$-ray microanalysis and elemental mapping. Energy dispersive X-ray spectra were recorded from the acidocalcisomes of whole cells dried onto Formvar-coated grids. Control spectra were collected from regions adjacent to the acidocalcisomes and from the Formvar film. Specimens were analyzed in a LEO 912 Omega scanning transmission electron microscope. X-rays were collected for $200 \mathrm{~s}$ using a Li-drifted Si-detector (front area $30 \mathrm{~mm}^{2}$ ) equipped with an ATW atmospheric window. The microscope was operated at $80 \mathrm{kV}$ using a tungsten filament, in the scanning transmission (STEM) imaging mode, spot size was $40 \mathrm{~nm}$ and emission current $\sim 10 \mu \mathrm{A}$. Analyses were performed using a Link multichannel energy analyzer and Link ISIS 3.00 software (Oxford Instruments, Wiesbaden, Germany).

Determination of $\mathrm{H}^{+}$transport. Variations of $\mathrm{H}^{+}$were followed by measuring the changes in the absorbance spectrum of acridine orange using a CINTRA 20 spectrophotometer at the wavelength pair 493 530 , at room temperature $\left(25^{\circ} \mathrm{C}\right)$. Cells $(1 \mathrm{mg} / \mathrm{ml})$ were added to a reaction medium containing $125 \mathrm{mM}$ sucrose, $65 \mathrm{mM} \mathrm{KCl}, 2 \mathrm{mM}$ $\mathrm{MgCl}_{2}, 2 \mathrm{mM}$ Pi-Tris, $10 \mathrm{mM}$ Hepes-KOH buffer, $\mathrm{pH} 7.2,1,2 \mu \mathrm{g} / \mathrm{ml}$ oligomycin, $125 \mu \mathrm{M}$ EGTA, $1 \mu \mathrm{g} / \mathrm{ml}$ acridine orange, and $80 \mu \mathrm{M}$ digitonin. $\mathrm{NH}_{4} \mathrm{Cl}(5 \mathrm{mM})$ was added when indicated. The reaction started with the indicated amount of PPi. The figures shown are representative of at least three experiments.

Immunofluorescence microscopy. Cells fixed in freshly prepared 4\% formaldehyde were allowed to adhere to poly(L-lysine)-coated coverslips, permeabilized with $0.3 \%$ Triton $\mathrm{X}-100$ for $3 \mathrm{~min}$, and blocked with $50 \mathrm{mM}$ ammonium chloride and $3 \%$ bovine serum albumin in PBS. Immunofluorescence was carried out using a 1:100 dilution of monoclonal antibodies raised against a peptide sequence of the $T$. cruzi $\mathrm{V}-\mathrm{H}^{+}$-PPase [25] and Alexa fluor-coupled goat anti-mouse IgG secondary antibody (1:300). Images were obtained in a confocal laser scanning microscope (Zeiss CLSM 310).

Chemicals. Oligomycin, carbonylcyanide $p$-trifluoromethoxiphenylhydrazone (FCCP), $N$-ethyl-maleimide (NEM), imidodiphosphate (IDP), sodium fluoride (NaF), pyrophosphate (PPi), acridine orange, and digitonin were purchased from Sigma Chemical (St. Louis, MO). All other reagents were of analytical grade. 


\section{Results}

\section{Electron microscopy characterization of acidocalcisomes}

Energy-filtering transmission electron microscopy (contrast tuning) of $L$. wallacei showed many electron dense vacuoles with an average diameter of $200 \mathrm{~nm}$. As shown before [17], X-ray microanalysis of the dense vacuoles showed a considerable amount of sodium, magnesium, phosphorus, potassium, calcium, iron, zinc, and oxygen (Fig. 1). This elemental composition is consistent with that previously described for the acidocalci-
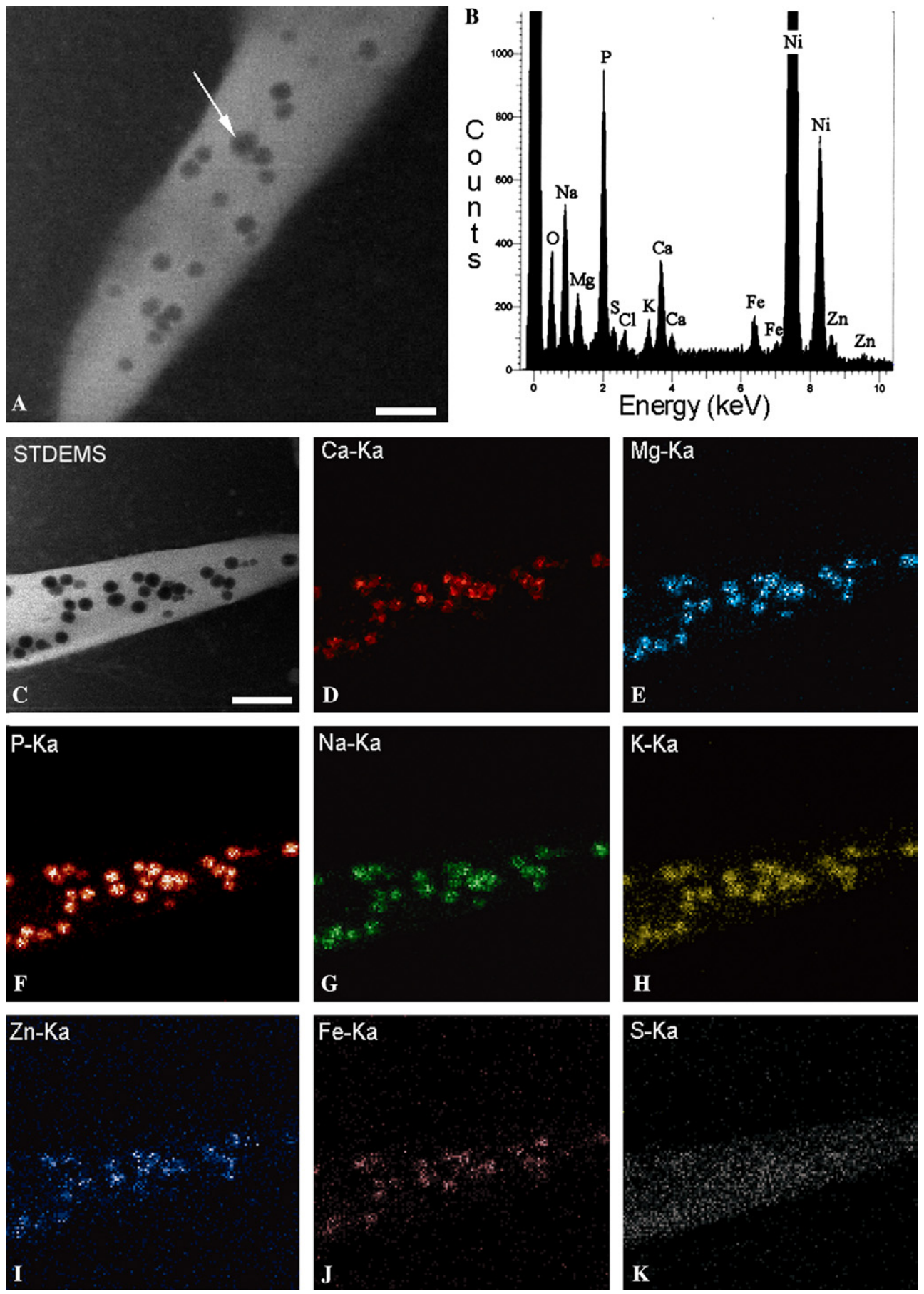

Fig. 1. Presence of acidocalcisomes in promastigotes of $L$. wallacei. (A) Electron spectroscopic imaging of whole unfixed $L$. wallacei promastigote ( $\Delta E$ between 60 and $80 \mathrm{eV}$ ). (B) Corresponding X-ray spectrum of the acidocalcisome pointed out in (A). Copper peaks in the spectrum came from the support grid and titanium peaks from the specimen holder. Carbon and chlorine signals were similar in the acidocalcisomes and control regions (cytoplasm). (C) Electron spectroscopic image of a portion of a whole promastigote ( $\Delta E$ between 60 and $80 \mathrm{eV}$ ). Elemental images of the cell displayed in (D-K) corresponding to: calcium; magnesium; phosphorus; sodium; potassium; zinc; iron; and sulfur. Scale bars: (A) $3.0 \mu \mathrm{M}$ (inset $400 \mathrm{~nm})$, (C) $800 \mathrm{~nm}$. 
somes of several trypanosomatids $[9,10,31,32,36,37]$ Elemental mapping showed that, except for sulfur, which was mostly detected in the cytoplasm, most of these elements were restricted to the acidocalcisome matrix (Fig. 1).

\section{Localization of the vacuolar proton pyrophosphatase}

Monoclonal antibodies raised against a peptide sequence of $T$. cruzi V-PPase, which has been shown to cross-react with the $\mathrm{H}^{+}$-PPase of other microorganisms $[16,25]$, were used to investigate whether this pump was also present in $L$. wallacei. Results revealed labeling on the plasma membrane and an intracellular punctuate staining pattern with number, size, and distribution similar to those of the electron dense organelles seen in whole cell images (Fig. 2).

\section{Pyrophosphate-driven proton uptake in permeabilized cells}

Mechanisms of proton uptake by acidocalcisomes in trypanosomatids and apicomplexan parasites have been demonstrated with the use of digitonin permeabilized cells, incubated in the presence of acridine orange $[6,20,21]$. In experiments of $\mathrm{H}^{+}$transport in $L$. wallacei, the addition of pyrophosphate (PPi) to digitonin permeabilized cells incubated in $65 \mathrm{mM} \mathrm{KCl}$ plus $125 \mathrm{mM}$ sucrose was followed by a fast decrease in absorbance of acridine orange, indicating proton uptake by intracellular organelles (acidocalcisomes) (Fig. 3). The activity was dependent on pyrophosphate concentration with minimum concentration to detect proton uptake around $20 \mu \mathrm{M}$ PPi and maximum activity in the concentration range of $500 \mu \mathrm{M}$ PPi. No further activity was detected at higher concentrations. Subsequent addition of nigericin, a $\mathrm{K}^{+} / \mathrm{H}^{+}$exchanger, or $\mathrm{NH}_{4} \mathrm{Cl}$ induced a fast release of protons from the intracellular vacuoles of the parasite (Fig. 3). Kinetics of pyrophosphate-dependent proton uptake in reaction media adjusted to different $\mathrm{pHs}$ showed that the activity was optimal in the $\mathrm{pH}$

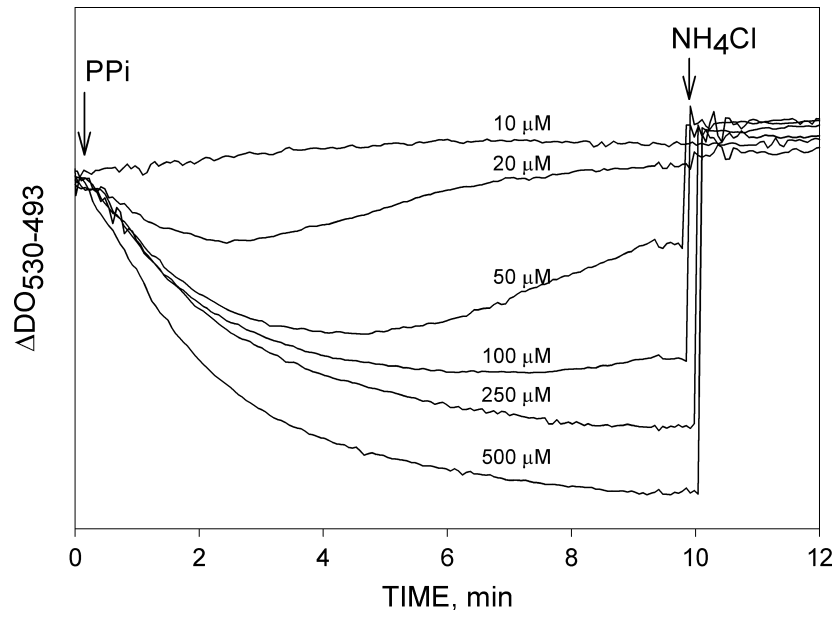

Fig. 3. Proton uptake promoted by different concentrations of PPi. The cells $(1 \mathrm{mg} / \mathrm{ml})$ were added to a medium containing $130 \mathrm{mM}$ sucrose, $65 \mathrm{mM} \mathrm{KCl}, 10 \mathrm{mM}$ Hepes-KOH, pH 7.2, $2 \mathrm{mM}$ Pi-Tris, $125 \mu \mathrm{M}$ EGTA, $1 \mu \mathrm{g} / \mathrm{ml}$ antimycin A, $2 \mu \mathrm{g} / \mathrm{ml}$ oligomycin, and $1 \mu \mathrm{g} / \mathrm{ml}$ acridine orange. Afterwards $80 \mu \mathrm{M}$ digitonin was added. Two minutes later, the reaction was started by the addition of the indicated amount of PPi. $\mathrm{NH}_{4} \mathrm{Cl}(5 \mathrm{mM})$ was added when indicated.

range 7.5-8.0 (Fig. 4A). No $\mathrm{H}^{+}$uptake was detected when, instead of PPi, $2 \mathrm{mM}$ ATP was used as substrate.

\section{Effect of buffer composition on pyrophosphate-dependent proton uptake}

The effect of composition of the reaction medium on the activity of the $\mathrm{H}^{+}$-PPase was tested by replacing $125 \mathrm{mM}$ sucrose plus $65 \mathrm{mM} \mathrm{KCl}$ reaction medium by a medium containing different concentrations of $\mathrm{KCl}$, $\mathrm{NaCl}$, choline- $\mathrm{Cl}$, and sucrose, yet maintaining the osmolarity constant. Results showed maximal activity in a $130 \mathrm{mM} \mathrm{KCl}$ reaction medium with decreasing activities in media containing lower concentrations of $\mathrm{K}^{+}$(Fig. 4B). Replacement of $130 \mathrm{mM} \mathrm{KCl}$ by $130 \mathrm{mM} \mathrm{NaCl}$ or choline-Cl resulted in very low $\mathrm{H}^{+}$uptake, while $260 \mathrm{mM}$ sucrose was ineffective in activating the V-H ${ }^{+}$-PPase (Fig. 4B).
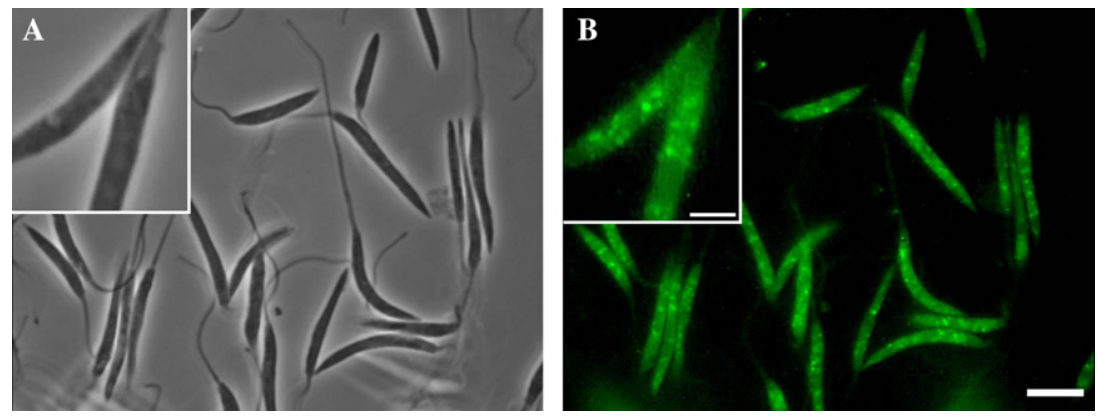

Fig. 2. Indirect inmunofluorescence analysis of $\mathrm{V}-\mathrm{H}^{+}$-PPase in $L$. wallacei. Phase contrast (A) and fluorescence (B) images of $L$. wallacei using antibodies raised against a peptide sequence of the $T$. cruzi $\mathrm{V}-\mathrm{H}^{+}$PPase, as described under Materials and methods. Images of an isolate cell are shown with a greater amplification in the insets. (B) Intense labeling of intracellular vesicles. Scale bars: (A) $10 \mu \mathrm{M}$, (A inset) $2.5 \mu \mathrm{M}$. 

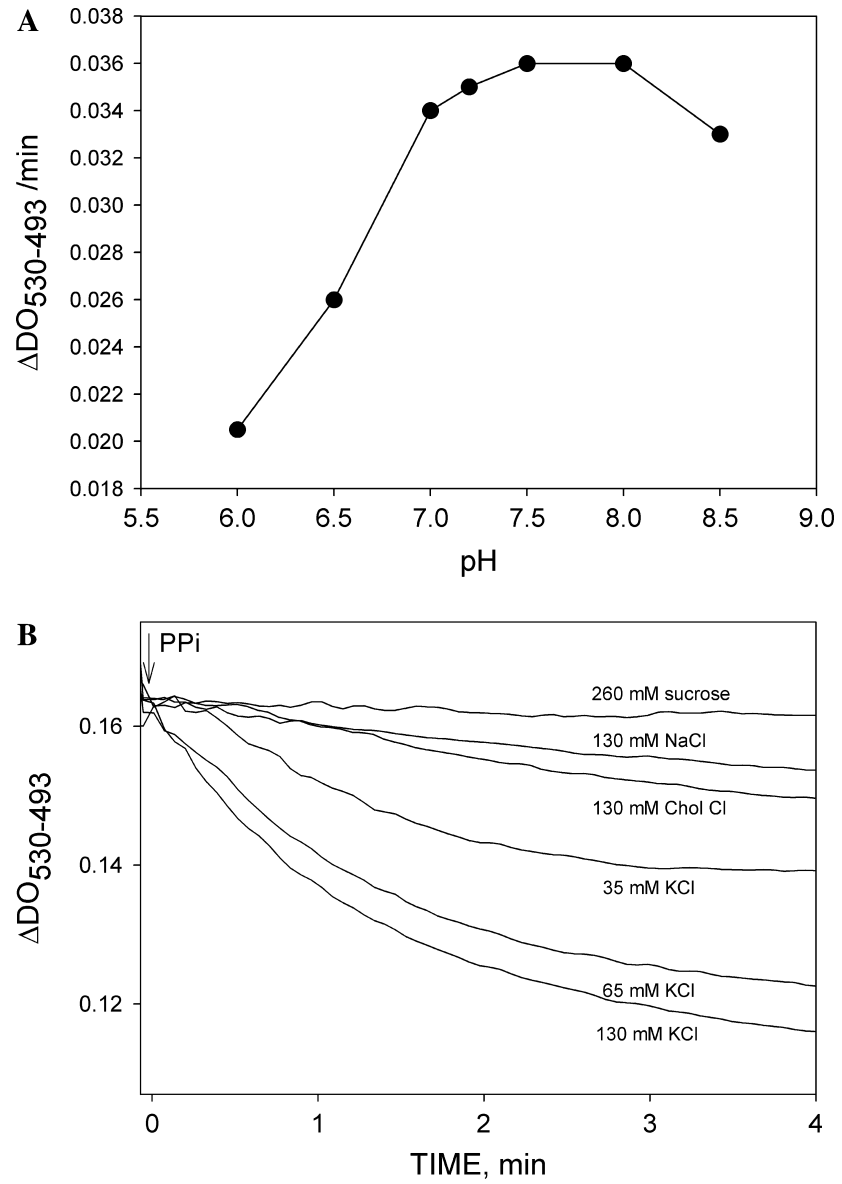

Fig. 4. Effect of medium composition on PPi-dependent proton uptake. (A) Dependence on $\mathrm{pH}$. Experimental conditions were as described in the legend of Fig. 3 with the same buffer adjusted to different $\mathrm{pH}$ values. The values represent the initial rate of proton uptake after the addition of $500 \mu \mathrm{M}$ PPi. (B) Effect of ionic composition. The cells $(1 \mathrm{mg} / \mathrm{ml})$ were added to a medium containing $10 \mathrm{mM}$ Hepes-Tris, pH 7.2, $2 \mathrm{mM}$ Pi-Tris, $125 \mu \mathrm{M}$ EGTA, $1 \mu \mathrm{g} / \mathrm{ml}$ antimycin A, $2 \mu \mathrm{g} / \mathrm{ml}$ oligomycin, $1 \mu \mathrm{g} / \mathrm{ml}$ acridine orange, and $80 \mu \mathrm{M}$ digitonin. $\mathrm{KCl}, \mathrm{NaCl}$ or choline- $\mathrm{Cl}$ was included in the media as indicated in the curves. In the curves with 35 and $65 \mathrm{mM} \mathrm{KCl}$, sucrose was added to have a final osmolarity of $260 \mathrm{mOsm}$. PPi $(500 \mu \mathrm{M})$ was added when indicated.

\section{Inhibition by IDP and the effect of ionophores}

Proton uptake was inhibited by imidodiphosphate (IDP), a non-hydrolysable pyrophosphate analogue, in a dose-dependent manner (Fig. 5A). Full inhibition of the $\mathrm{H}^{+}$-PPase activity was observed with $0.5 \mathrm{mM}$ PPi at IDP concentrations in the range of $5-10 \mathrm{mM}, 2 \mathrm{mM}$ being enough to substantially inhibit the pump. However, when pyrophosphate was reduced a significant increase in the IDP sensitivity was observed, characterizing a competitive inhibition (Fig. 5B). With $50 \mu \mathrm{M}$ of $\mathrm{PPi}$, proton release in control cells could be observed within 4 min of reaction, but this did not occur when IDP was added to the reaction medium. This pattern was most likely the consequence of a fast PPi

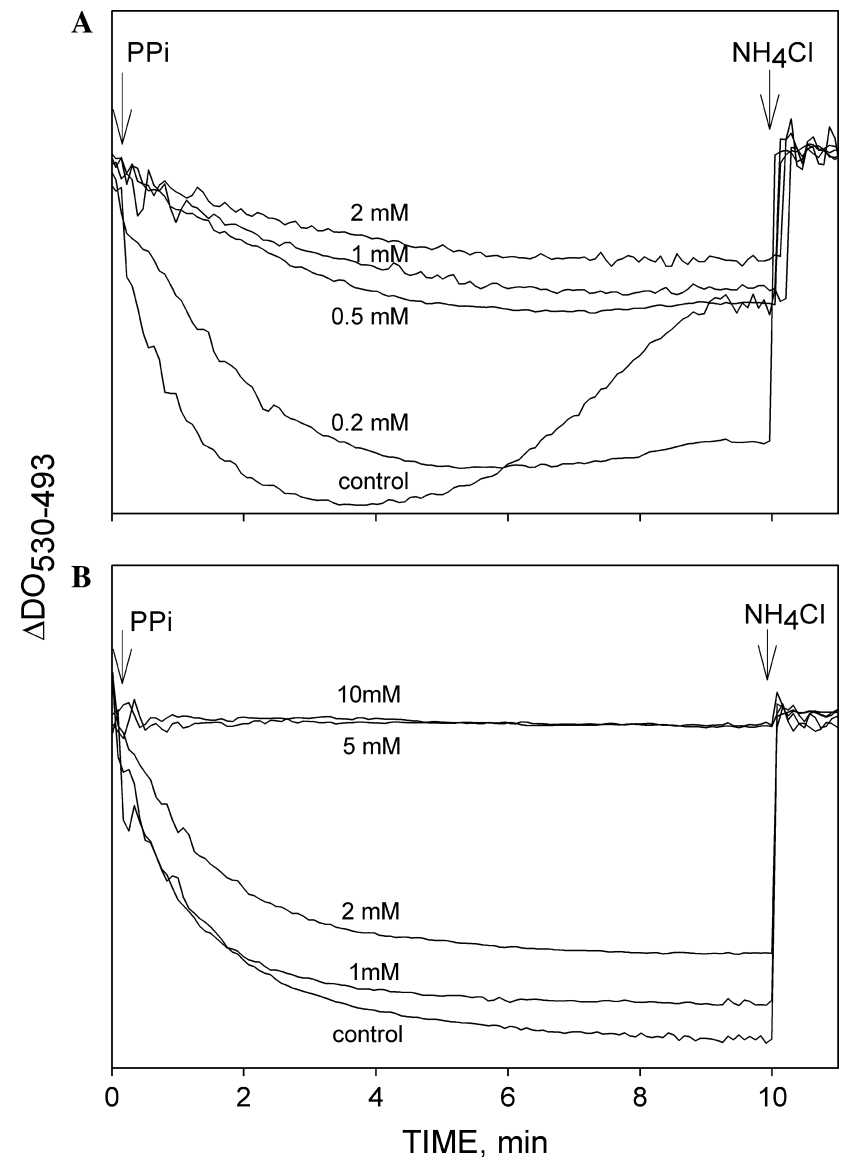

Fig. 5. Inhibition of proton uptake by imidodiphosphate (IDP). The cells $(1 \mathrm{mg} / \mathrm{ml})$ were added to the medium described in Fig. 3. PPi concentration was $50 \mu \mathrm{M}$ (A) or $500 \mu \mathrm{M}$ (B). IDP concentrations are indicated in the graphic.

disappearance in the media due to an acidocalcisomal leak of $\mathrm{H}^{+}$. Sodium orthovanadate $(2 \mathrm{mM})$, a known P-type ATPase inhibitor, and $N$-ethyl-maleimide (NEM, $100 \mu \mathrm{M}$ ), a thiol reagent, had no significant effect (data not shown). Addition of FCCP, a proton ionophore, completely collapsed the $\mathrm{H}^{+}$gradient whereas valinomycin, a $\mathrm{K}^{+}$ionophore, slightly stimulated the uptake of acridine orange driven by PPi (Fig. 6), similar to what was described for T. cruzi [5], suggesting that the pumping of $\mathrm{H}^{+}$is electrogenic.

\section{Presence of cation $/ \mathrm{H}^{+}$exchangers in the acidocalcisomes}

Cation/proton exchangers have been reported to have a role in the mechanisms of cation uptake and release by the acidocalcisomes. $\mathrm{A} \mathrm{Na}^{+} / \mathrm{H}^{+}$exchanger that may participate in $\mathrm{Na}^{+}$uptake has been described in the acidocalcisomes of $T$. brucei and Leishmania donovani [30,38]. Furthermore, a $\mathrm{Ca}^{2+} / \mathrm{H}^{+}$counter-transporting ATPase and $\mathrm{Ca}^{2+} / n \mathrm{H}^{+}$exchanger involved in calcium uptake and release by acidocalcisomes have also been described $[6,9]$. To investigate whether these exchangers were also present in acidocalcisomes of $L$. wallacei, 


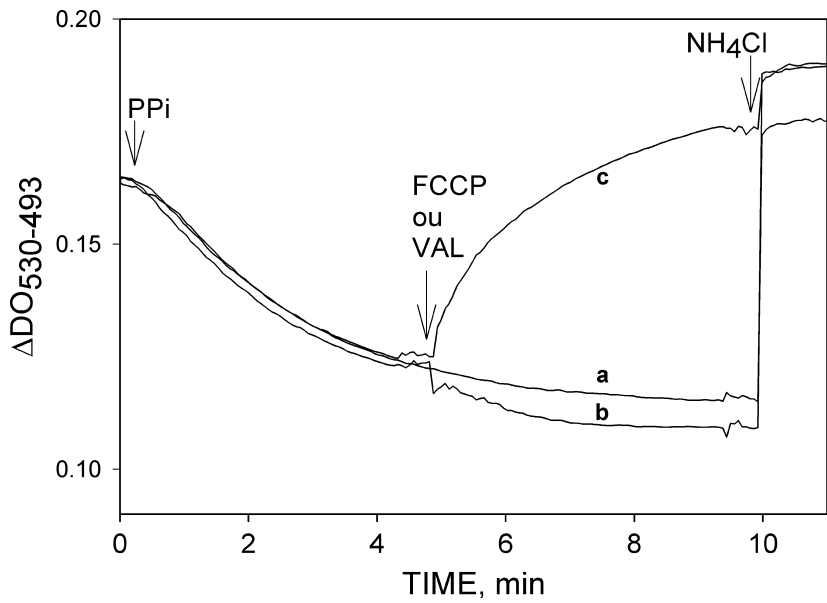

Fig. 6. Effect of ionophores on proton uptake. The cells $(1 \mathrm{mg} / \mathrm{ml})$ were added to the medium described in Fig. 3. No addition (curve a), valinomycin (10 $\mu \mathrm{M}$, curve b), FCCP $(10 \mu \mathrm{M}$, curve c). PPi $(500 \mu \mathrm{M})$ and $\mathrm{NH}_{4} \mathrm{Cl}(5 \mathrm{mM})$ were added when indicated.

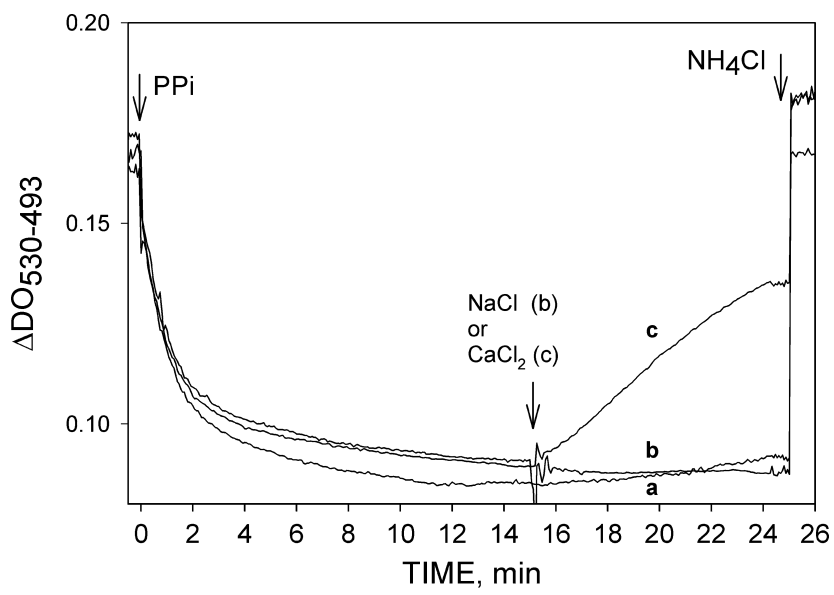

Fig. 7. Effect of $\mathrm{Ca}^{2+}$ and $\mathrm{Na}^{+}$on $\mathrm{H}^{+}$uptake. The cells $(1 \mathrm{mg} / \mathrm{ml})$ were added to the medium described in Fig. 3. No addition (a), $\mathrm{NaCl}$ (40 $\mathrm{mM}$, curve b) and $\mathrm{CaCl}_{2}(250 \mu \mathrm{M}$, curve c) were added at $15 \mathrm{~min}$. PPi $(500 \mu \mathrm{M})$ and $\mathrm{NH}_{4} \mathrm{Cl}(5 \mathrm{mM})$ were added when indicated.

$250 \mu \mathrm{M} \mathrm{CaCl}_{2}$ (enough to give $125 \mu \mathrm{M}$ of free $\mathrm{Ca}^{2+}$ ) or $40 \mathrm{mM} \mathrm{Na}{ }^{+}$was added to the reaction medium after PPi-driven proton uptake. Results showed that $\mathrm{Ca}^{2+}$ could effectively release $\mathrm{H}^{+}$from intracellular organelles, suggesting the presence of a $\mathrm{Ca}^{2+} / n \mathrm{H}^{+}$countertransporting system in the acidocalcisomes, whereas $\mathrm{Na}^{+}$was unable to release $\mathrm{H}^{+}$, suggesting that this exchanger is absent in the acidocalcisomes of $L$. wallacei (Fig. 7).

\section{Discussion}

In this work, we report the presence of acidocalcisomes in L. wallacei, a trypanosomatid parasite that is able to differentiate into cystic forms. Several functions have been attributed to the acidocalcisomes, such as control of cytosolic $\mathrm{pH}$, ion homeostasis, storage of high energy compounds, osmoregulation, and a role in the biosynthesis of sphingolipids (reviewed in [39]). It has also been postulated that acidocalcisomes have a functional role in the adaptation of heteroxenic parasites such as Trypanosoma and Leishmania to different environmental conditions encountered in their different hosts during their life cycle, a condition that is mandatory for a successful infection by these parasites [14,39]. Despite being able to infect only a single host, $L$. wallacei also faces different environments during its life cycle. The parasite infects different portions of the insect gut, which have different physicochemical properties such as differences in $\mathrm{pH}$, ionic composition, and osmotic pressure. Variations of such conditions in the extracellular environment are believed to lead $L$. wallacei to differentiate into cystic forms [1]. As acidocalcisomes of $L$. wallacei accumulate several ions, as seen by $\mathrm{X}$ ray elemental mapping, and present a $\mathrm{V}-\mathrm{H}^{+}$-PPase activity, it is possible that these organelles might also play a role on the adaptation mechanisms of the parasite to changes in the environmental conditions, functioning in ion homeostasis and $\mathrm{pH}$ stasis, being an alternative mechanism of environmental sensing by this parasite.

The $\mathrm{V}-\mathrm{H}^{+}$-PPase is an electrogenic proton pump that has so far been described in bacteria [26], microorganisms $[8,40]$, plants (reviewed in [41]), and recently found in insects [42], being absent in mammalians. The $\mathrm{H}^{+}$translocating pyrophosphatase activity characterized here was shown to be located in acidocalcisomes in accordance with previous results found in different trypanosomatids [39]. This activity had optimum $\mathrm{pH}$ between 7.5 and 8.0 (Fig. 4A), was stimulated by $\mathrm{K}^{+}$but minimally by $\mathrm{Na}^{+}$or choline ${ }^{+}$(Fig. 4B), insensitive to NEM and vanadate (data not shown), and fully inhibited by IDP (Figs. 5A and B). The $\mathrm{H}^{+}$pumping activity seems to be electrogenic since increasing the $\mathrm{K}^{+}$permeability with valinomycin, that would collapse any membrane potential generated by the ion pumping, increased the efficiency of the uptake. Two types of $\mathrm{V}-\mathrm{H}^{+}$-PPase have been cloned and characterized from A. thaliana, AVP1 [43] and AVP2 [44]. AVP1 is stimulated by $\mathrm{K}^{+}$ and AVP2 is insensitive to this ion. In $L$. donovani, the $\mathrm{V}-\mathrm{H}^{+}$-PPase activity was shown to be dependent on $\mathrm{K}^{+}$[9]. In contrast, the type II $\mathrm{H}^{+}$-PPase insensitive to potassium has been described in Plasmodium falciparum [45]. So, the PPi dependent $\mathrm{H}^{+}$transport observed in $L$. wallacei can be considered as an AVP1 type. The release of $\mathrm{H}^{+}$with the addition $\mathrm{Ca}^{2+}$ indicates the presence of a $\mathrm{Ca}^{2+} / \mathrm{H}^{+}$exchanger in acidocalcisomes of $L$. wallacei. However, in contrast to what has been previously observed in T. brucei $[38]$ and $L$. donovani $[10,30] \mathrm{Na}^{+}$ was incapable of releasing $\mathrm{H}^{+}$, indicating the absence of a $\mathrm{Na}^{+} / \mathrm{H}^{+}$exchanger in the acidocalcisomes of this parasite. 
We were unable to find evidence for other $\mathrm{pH}$ regulatory mechanisms in this parasite. It is possible that the $\mathrm{H}^{+}$-ATPase complex in this parasite dissociates during permeabilization, losing its peripheral subunits and becoming inactive. However, we do not discard a possible presence of an ATP-driven proton uptake by $L$. wallacei since this has been shown in trypanosomatid parasites analyzed by alternative methods.

Together, these results suggest that the electron dense vacuoles of promastigote $L$. wallace $i$ and the acidocalcisomes described in other trypanosomatids and apicomplexan parasites are representative of the same class of organelles.

\section{Acknowledgments}

We thank Dr. Roberto Docampo for the gift of the monoclonal antibodies against $T$. cruzi $\mathrm{H}^{+}$-PPase. This work was supported by grants from the Conselho Nacional de Desenvolvimento Científico e Tecnológico (CNPq), Fundação de Amparo a Pesquisa do Estado do Rio de Janeiro (FAPERJ), PRONEX (number 7697100000), and Deutsche ForschungsgemeinshaftDFG (to H.P.). B.L.M.M. was the recipient of a doctoral fellowship and K.M. the recipient of a post doctoral fellowship from $\mathrm{CNPq}$ and a travel fellowship from DFG/TR-SFB11. LCSM was the recipient of an undergraduate fellowship from CNPq. We thank Ms. Rosângela Ferreira for her excellent technical assistance.

\section{References}

[1] A. Romeiro, A. Solé-Cava, M.A. Sousa, W. de Souza, M. Attias, Ultrastructural and biochemical characterization of promastigote and cystic forms of Leptomonas wallacei $n$. sp. isolated from the intestine of its natural host Oncopeltus fasciatus (Hemiptera:Lygaeidae), J. Eukaryot. Microbiol. 47 (2000) 208-220.

[2] A. Romeiro, E.M. Saraiva, W. de Souza, M. Attias, Leptomonas wallacei shows distinct morphology and surface carbohydrates composition along the intestinal tract of its host Oncopeltus fasciatus (Hemiptera: Lygaeidae) and in axenic culture, J. Eukaryot. Microbiol. 50 (2003) 409-416.

[3] A. Romeiro, L.H.L. Monteiro, W. de Souza, M. Attias, Interaction of Leptomonas wallacei with the intestinal tract of its natural host Oncopeltus fasciatus (Hemiptera: Lygaeidae), J. Invertebr. Pathol. 82 (2003) 41-49.

[4] L. Vieira, $\mathrm{pH}$ and volume homeostasis in trypanosomatids: current views and perspectives, Biochim. Biophys. Acta 1376 (1998) 221-241.

[5] D.A. Scott, R. Docampo, Two types of $\mathrm{H}^{+}$-ATPases are involved in the acidification of internal compartments in Trypanosoma cruzi, Biochem. J. 331 (1998) 583-589.

[6] A.E. Vercesi, S.N.J. Moreno, R. Docampo, $\mathrm{Ca}^{2+} / \mathrm{H}^{+}$exchange in acidic vacuoles of Trypanosoma brucei, Biochem. J. 304 (1994) 227-233

[7] D.A. Scott, S.N.J. Moreno, R. Docampo, $\mathrm{Ca}^{2+}$ storage in Trypanosoma brucei: the influence of cytoplasmic $\mathrm{pH}$ and importance of vacuolar acidity, Biochem. J. 310 (1995) 780-794.
[8] D.A. Scott, W. de Souza, M. Benchimol, L. Zhong, H.G. Lu, S.N.J. Moreno, R. Docampo, Presence of a plant-like proton pumping pyrophosphatase in acidocalcisomes of Trypanosoma cruzi, J. Biol. Chem. 273 (1998) 22151-22158.

[9] C.O. Rodrigues, D.A. Scott, R. Docampo, Characterization of a vacuolar pyrophosphatase in Trypanosoma brucei and its localization to acidocalcisomes, Mol. Cell. Biol. 19 (1999) 7712-7723.

[10] C.O. Rodrigues, D.A. Scott, R. Docampo, Presence of a vacuolar $\mathrm{H}^{+}$pyrophosphatase in promastigotes of Leishmania donovani and its localization to a different compartment from the vacuolar $\mathrm{H}^{+}$ATPase, Biochem. J. 340 (1999) 759-766.

[11] K. Miranda, A.E. Vercesi, R. Catisti, W. de Souza, C.O. Rodrigues, R. Docampo, P-type proton ATPases are involved in intracellular calcium and proton uptake in the plant parasite Phytomonas francai, J. Eukaryot. Microbiol. 52 (2005) 55-60.

[12] R. Docampo, D.A. Scott, A.E. Vercesi, S.N.J. Moreno, Intracelullar $\mathrm{Ca}^{2+}$ storage in acidocalcisomes of Trypanosoma cruzi, Biochem. J. 310 (1995) 1005-1012.

[13] H. Lu, L. Zhong, K.P. Chang, R. Docampo, Intracelullar $\mathrm{Ca}^{2+}$ pool content and signalling, and expression of a calcium pump are linked to virulence in Leishmania mexicana amazonensis, J. Biol. Chem. 272 (1997) 9464-9473.

[14] K. Miranda, R. Docampo, O. Grillo, A. Franzen, M. Attias, A.E. Vercesi, H. Plattner, J. Hentschel, W. de Souza, Dynamics of polymorphism of acidocalcisomes in Leishmania parasites, Histochem. Cell Biol. 121 (2004) 407-418.

[15] K. Miranda, C.O. Rodrigues, R. Catisti, A.E. Vercesi, H. Plattner, J. Hentschel, W. de Souza, R. Docampo, Acidocalcisomes of Phytomonas françai possess distinct morphological characteristics and contain iron, Microsc. Microanal. 10 (2004) 647-655.

[16] L.C.A.S. Medeiros, B.L.M. Moreira, K. Miranda, W. de Souza, H. Plattner, J. Hentschel, H. Barrabin, A proton pumping pyrophosphatase in acidocalcisomes of Herpetomonas sp., Mol. Biochem. Parasitol. 140 (2005) 175-182.

[17] K. Miranda, R. Docampo, O. Grillo, W. de Souza, Acidocalcisomes of trypanosomatids have species-specific elemental composition, Protist 155 (2004) 395-405.

[18] N. Marchesini, S. Luo, C.O. Rodrigues, S.N.J. Moreno, R. Docampo, Acidocalcisomes and a vacuolar $\mathrm{H}^{+}$-pyrophosphatase in malaria parasites, Biochem. J. 347 (2000) 243-253.

[19] S. Luo, N. Marchesini, S.N.J. Moreno, R. Docampo, A plant-like vacuolar $\mathrm{H}^{+}$-pyrophosphatase in Plasmodium falciparum, FEBS Lett. 460 (1999) 217-220.

[20] S.N.J. Moreno, L. Zhong, Acidocalcisomes in Toxoplasma gondii tachyzoites, Biochem. J. 813 (1996) 655-659.

[21] S. Luo, M. Vieira, J. Graves, L. Zhong, S.N.J. Moreno, A plasma membrane-type $\mathrm{Ca}^{2+}$-ATPase co-localizes with a vacuolar $\mathrm{H}^{+}$. pyrophosphatase to acidocalcisomes of Toxoplasma gondii, EMBO J. 20 (2001) 55-64.

[22] C.O. Rodrigues, F.A. Ruiz, P. Rohloff, D.A. Scott, S.N.J. Moreno, Characterization of isolated acidocalcisomes from Toxoplasma gondii tachyzoites reveals a novel pool of hydrolyzable polyphosphate, J. Biol. Chem. 277 (2002) 48650-48656.

[23] F.A. Ruiz, N. Marchesini, M. Seufferheld, R. Docampo, The polyphosphate bodies of Chlamydomonas reinhardtii possess proton-pumping pyrophosphatase and are similar to acidocalcisomes, J. Biol. Chem. 276 (2001) 46196-46203.

[24] N. Marchesini, F.A. Ruiz, M. Vieira, R. Docampo, Acidocalcisomes are functionally linked to the contractile vacuole of Dictyostelium discoideum, J. Biol. Chem. 277 (2002) 8146-8153.

[25] M. Seufferheld, M.C.F. Vieira, F.A. Ruiz, C.O. Rodrigues, S.N.J. Moreno, R. Docampo, Identification of organelles in bacteria similar to acidocalcisomes of unicellular eukaryotes, J. Biol. Chem. 278 (2003) 29971-29978.

[26] M. Seufferheld, C.R. Lea, M. Vieira, E. Oldfield, R. Docampo, The $\mathrm{H}^{+}$-pyrophosphatase of Rhodospirillum rubrum is predomi- 
nantly located in polyphosphate-rich acidocalcisomes, J. Biol. Chem. 279 (2004) 51193-51202.

[27] M. Benchimol, W. de Souza, N. Vanderheyden, L. Zhong, H.G. Lu, S.N.J. Moreno, R. Docampo, Functional expression of a vacuolartype $\mathrm{H}^{+}$-ATPase in the plasma membrane and intracellular vacuoles of Trypanosoma cruzi, Biochem. J. 332 (1998) 695-702.

[28] S.N.J. Moreno, L. Zhong, W. de Souza, M. Benchimol, Vacuolartype $\mathrm{H}^{+}$-ATPase regulates cytoplasmic $\mathrm{pH}$ in Toxoplasma gondii, Biochem. J. 330 (1998) 853-860.

[29] H.G. Lu, L. Zhong, W. de Souza, M. Benchimol, S.N.J. Moreno, R. Docampo, $\mathrm{Ca}^{2+}$ content and expression of an acidocalcisomal calcium pump are elevated in intracellular forms of Trypanosoma cruzi, Mol. Cell. Biol. 18 (1998) 2309-2323.

[30] A.E. Vercesi, C.O. Rodrigues, R. Catisti, R. Docampo, Presence of a $\mathrm{Na}^{+} / \mathrm{H}^{+}$exchanger in acidocalcisomes of Leishmania donovani and their alkalization by anti-leishmanial drugs, FEBS Lett. 473 (2000) 203-206.

[31] D.A. Scott, R. Docampo, J.A. Dvorak, S. Shi, R.D. Leapman, In situ compositional analysis of acidocalcisomes in Trypanosoma cruzi, J. Biol. Chem. 272 (1997) 28020-28029.

[32] K. Miranda, M. Benchimol, R. Docampo, W. de Souza, The fine structure of acidocalcisomes in Trypanosoma cruzi, Parasitol. Res. 86 (2000) 373-384.

[33] J.A. Urbina, B. Moreno, S. Vieerkotter, E. Oldfield, G. Payares, C. Sanoja, B.N. Bailey, W. Yan, D.A. Scott, S.N.J. Moreno, R. Docampo, Trypanosoma cruzi contains major pyrophosphate stores and its growth in vitro is blocked by pyrophosphate analogs, J. Biol. Chem. 274 (1999) 33609-33615.

[34] A.F. Correa, L.R. Andrade, M.J. Soares, Elemental composition of acidocalcisomes of Trypanosoma cruzi bloodstream trypomastigote forms, Parasitol. Res. 88 (2001) 875-880.

[35] B. Moreno, J.A. Urbina, E. Oldfield, B.N. Bailey, C.O. Rodrigues, R. Docampo, ${ }^{31} \mathrm{P}$ NMR spectroscopy of Trypanosoma brucei, Trypanosoma cruzi, and Leishmania major. Evidence for high levels of condensed inorganic phosphates, J. Biol. Chem. 275 (2000) 28356-28362.

[36] J.A. Dvorak, J.C. Engel, R.D. Leapman, C.R. Swyt, P.A. Pella, Trypanosoma cruzi: elemental composition of cloned stocks, Mol. Biochem. Parasitol. 31 (1988) 19-26.

[37] A. LeFurgey, P. Ingram, J. Blum, Compartmental responses to acute osmotic stress in Leishmania major result in rapid loss of $\mathrm{Na}^{+}$and $\mathrm{Cl}^{-}$, Comp. Biochem. Physiol. 128 (2001) 385-394.

[38] A.E. Vercesi, R. Docampo, Sodium-proton exchange stimulates $\mathrm{Ca}^{2+}$ release from acidocalcisomes of Trypanosoma brucei, Biochem. J. 315 (1996) 265-270.

[39] R. Docampo, W. de Souza, K. Miranda, P. Rohloff, S.N.J. Moreno, Acidocalcisomes - conserved from bacteria to man, Nat. Rev. Microbiol. 3 (2005) 251-261.

[40] M.T. McIntosh, A.B. Vaidya, Vacuolar type $\mathrm{H}^{+}$pumping pyrophosphatases of parasitic protozoa, Int. J. Parasitol. 32 (2002) 1-14.

[41] M. Maeshima, Vacuolar $\mathrm{H}^{+}$-pyrophosphatase, Biochim. Biophys. Acta 1465 (2000) 37-51.

[42] L.S. Motta, W.S. da Silva, D.M. Oliveira, W. de Souza, E.A. Machado, A new model for proton pumping in animal cells: the role of pyrophosphate, Insect Biochem. Mol. Biol. 34 (2004) 19-27.

[43] V. Sarafian, Y. Kim, R.J. Poole, P.A. Rea, Molecular cloning and sequence of cDNA encoding the pyrophosphate-energized vacuolar membrane proton pump of Arabidopsis thaliana, Proc. Natl. Acad. Sci. USA 89 (1992) 1775-1779.

[44] Y.M. Drodzwicz, J.C. Kissinger, P.A. Rea, AVP2, a sequencedivergent, $\mathrm{K}^{+}$-insensitive $\mathrm{H}^{+}$-translocating inorganic pyrophosphatase from Arabidopsis, Plant Physiol. 123 (2000) 353-362.

[45] E.J. Kim, R.G. Zhen, P.A. Rea, Site-directed mutagenesis of vacuolar $\mathrm{H}^{+}$-pyrophosphatase, J. Biol. Chem. 270 (1995) 2630 2635. 